\title{
Pulmonary Involvement in Acute Rheumatic Fever: A Case Report and Literature Review
}

\author{
Patrick Kenney ${ }^{1}$, Sarah McMullin ${ }^{2}$, Rabheh Abdul-Aziz ${ }^{3}$
}

1. Department of Medicine, Jacobs School of Medicine and Biomedical Sciences, University at Buffalo, Buffalo, USA 2. Department of Pediatrics, Jacobs School of Medicine and Biomedical Sciences, University at Buffalo, Buffalo, USA 3. Department of Pediatric Rheumatology, Jacobs School of Medicine and Biomedical Sciences, University at Buffalo, Buffalo, USA

Corresponding author: Rabheh Abdul-Aziz, raziz@upa.chob.edu

\begin{abstract}
Rheumatic pneumonia is a pulmonary complication of rheumatic fever, often with grave outcomes. It has been described sporadically in literature, most recently a decade ago. Here, we describe a case of a 12-yearold Native American girl presenting with chest pain, gastrointestinal complaints, and frequent nosebleeds. After the initial diagnosis with acute pericarditis, she was found to meet diagnostic criteria for rheumatic fever. Revised Jones criteria met included significantly elevated streptolysin O antibody and anti-DNase B, carditis, arthralgia, fever, and elevated inflammatory markers. Findings complicating the diagnosis were an elevated antinuclear antigen with a family history of systemic lupus erythematosus (SLE), hemoptysis, and a chest CT finding of right lower lobe alveolar hemorrhage as well as right-sided mediastinal adenopathy. The patient was discharged on day nine of admission after a course of high-dose methylprednisolone with prednisone taper, furosemide, enalapril, naproxen, monthly penicillin $\mathrm{G}$ injections, and multidisciplinary outpatient follow-up. A repeat chest CT scan three months later showed significant improvement. The pulmonary findings described in our patient are consistent with prior reports of rheumatic pneumonia, however, most prior cases described did not include high-resolution imaging. Our patient recovered well aside from complications secondary to mitral regurgitation, unlike many patients seen in our literature search who died due to early or later complications of pulmonary disease. Although acute rheumatic fever, and its pulmonary complications, is significantly less common than it once was, it remains a disease entity that should remain on the differential for multisystem rheumatic complaints.
\end{abstract}

Received 02/01/2020 Review began 02/03/2020 Review ended 03/14/2020 Published 03/16/2020

() Copyright 2020 Kenney et al. This is an open access article distributed under the terms of the Creative Commons Attribution License CC-BY 4.0., which permits unrestricted use, distribution, and reproduction in any medium, provided the original author and source are credited.
Categories: Pediatrics, Infectious Disease, Rheumatology

Keywords: acute rheumatic fever, rheumatic heart disease, carditis, rheumatic pneumonia, rheumatic fever, rheumatic pneumonitis

\section{Introduction}

Rheumatic fever was first described in the late 1600s by Sydenham as a differentiation between gout and rheumatoid arthritis [1]. For over 200 years, not much changed in our understanding of the disease until bacteriologic advances in the late 1800s helped identify a correlation between streptococcal pharyngitis and eventual onset of rheumatic fever [1]. The discovery of anti-streptolysin $O$ in the 1930s revolutionized the diagnosis and helped fully differentiate acute rheumatic fever (ARF) from other arthritides [1]. Following the development of the sulfonamides and penicillins in the late 1930s and their use in the prevention of ARF in the 1940s, antibiotics quickly became the mainstay of therapy [2]. There remains robust discussion on optimal doses, durations, and types of supplemental therapies, but long-term penicillin remains the most common therapy prescribed to prevent the recurrence of rheumatic fever [1-2].

The prevalence of acute rheumatic fever has declined significantly since the introduction of modern antibiotics [3]. Current estimates range from 0.6 to 3.7 cases per 100,000 per year in the United States, with higher rates in Hawaii and American Samoa [4-5]. That said, it is a diagnosis that should remain on the differential for clinicians in the outpatient, emergency, and inpatient settings primarily due to the morbidity associated with untreated group A streptococcus (GAS) infections. The modern diagnostic criteria were most recently updated in 2015 with the Revised Jones criteria [6]. In the text below, we describe an atypical presentation of advanced rheumatic fever with pulmonary complications consistent with prior reports of rheumatic pneumonia.

\section{Case Presentation}

A 12-year-old premenstrual female of Native American ancestry with mild intermittent asthma and recurrent self-resolving nosebleeds for the past several years presented to an outside institution with sharp, left-sided constant chest pain worsening on deep inspiration accompanied by shortness of breath starting the day of presentation. She also reported a five to six-day history of nausea, vomiting, diarrhea, and fevers as high as $103^{\circ} \mathrm{F}$ the day prior, two months of worsening polyarthralgias, weight loss of 5 kilograms (10\% body weight), and malaise. There was a family history of SLE in her paternal aunt and her mother was being followed by rheumatology for unspecified arthritis. 


\section{Cureus}

She was initially diagnosed with pericarditis based on classic electrocardiogram (EKG) findings,

including sinus tachycardia, ST elevations, and PR depressions throughout, with a significantly elevated erythrocyte sedimentation rate (ESR). She was transferred to our tertiary children's hospital for further management. Vital signs on arrival were significant for persistent tachycardia and intermittent hypoxemia requiring oxygen supplementation. She remained afebrile and with stable blood pressures. Physical exam during the first 24 hours of her stay demonstrated a friction rub and signs of fluid overload with pretibial pitting edema and jugular venous distention. Initial workup showed an elevated erythrocyte sedimentation rate (ESR) of $136 \mathrm{~mm} / \mathrm{hr}$ (normal $<20 \mathrm{~mm} / \mathrm{hr}$ ), and significant microcytic anemia with hemoglobin of $7.3 \mathrm{~g} / \mathrm{dL}$ (last checked at the age of four, when it was normal). Significant laboratory findings are noted in Table 1. 


\section{Cureus}

\begin{tabular}{|c|c|c|c|c|c|c|}
\hline \multirow[b]{2}{*}{ Leukocytes } & \multicolumn{3}{|c|}{ Normal range } & \multirow{2}{*}{$\begin{array}{l}\text { Presentation } \\
16.2\end{array}$} & \multirow[t]{2}{*}{ Day 1} & \multirow[t]{2}{*}{ Day 2} \\
\hline & 4.0 & to 10.5 & 10^9/L & & & \\
\hline Hemoglobin & 12.0 & to 15 & $\mathrm{~g} / \mathrm{dL}$ & 7.3 & & \\
\hline Platelets & 150 & to 450 & 10^9/L & 440 & & \\
\hline ESR & 0 & to 20 & $\mathrm{~mm} / \mathrm{hr}$ & 136 & & \\
\hline CRP & 0.2 & to 10 & $\mathrm{mg} / \mathrm{L}$ & 157 & & \\
\hline ANA - Nuclear Ab Titer & & $<1: 40$ & & & 1:1280 & \\
\hline DNA Double Strand Ab & & Negative & & & Negative & \\
\hline Streptolysin O Ab & 0 & to 199 & unit/mL & & & 2490 \\
\hline Anti Dnase B Titer & 0 & to 376 & unit/mL & & & 626 \\
\hline Cardiolipin Abs Qualitative & & & & & & Negative \\
\hline Cardiolipin Ag IgG & & & & & & Within normal limits \\
\hline Cardiolipin Ag IgM & & & & & & Within normal limits \\
\hline Dilute Russell Viper Venom Ratio & 0 & to 1.19 & units & & & 1.22 \\
\hline Beta 2 Glycoprotein 1 Ab & & & & & & Negative \\
\hline Rheumatoid Factor & & & & & & Within normal limits \\
\hline RNP Extractable Nuclear Ab & & & & & & Negative \\
\hline Smith Extractable Nuclear Ab & & & & & & Negative \\
\hline Sjogrens Syndrome-A ENA & & & & & & Negative \\
\hline Sjogrens Syndrome-B ENA & & & & & & Negative \\
\hline Histone Ab lgG & & & & & & Negative \\
\hline C3 & & & & & & Within normal limits \\
\hline C4 & & & & & & Within normal limits \\
\hline $\lg A$ & 70 & to 390 & $\mathrm{mg} / \mathrm{dL}$ & & & 622 \\
\hline $\lg G$ & 680 & to 1531 & $\mathrm{mg} / \mathrm{dL}$ & & & 2450 \\
\hline $\lg M$ & 50 & to 300 & $\mathrm{mg} / \mathrm{dL}$ & & & 145 \\
\hline Myeloperoxidase Ab IgG & & & & & & Within normal limits \\
\hline C-ANCA & & & & & & Negative $(<1: 10)$ \\
\hline P-ANCA & & & & & & Negative $(<1: 10)$ \\
\hline Atypical P-ANCA & & & & & & Negative $(<1: 10)$ \\
\hline Serine Proteinase Ab IgG & & & & & & Within normal limits \\
\hline Angiotensin Converting Enzyme & & & & & & Within normal limits \\
\hline Blastomyces Ab & & & & & & Negative \\
\hline
\end{tabular}

\section{TABLE 1: Pertinent positive and negative laboratory findings from early in the hospital course}

Days refer to the hospital day on which samples were drawn; results were available as described in the body of the article.

Ab - Antibody, ENA - Extractable Nuclear Antigen, C-ANCA - Cytoplasmic antineutrophil cytoplasmic antibodies, P-ANCA - Perinuclear antineutrophil cytoplasmic antibodies 


\section{Cureus}

A subsequent transthoracic echocardiogram demonstrated increased echogenicity of the pericardium without evidence of pericardial effusion, consistent with pericarditis. Findings were also significant for moderate mitral regurgitation with associated significant left atrial enlargement, tricuspid regurgitation, trivial aortic insufficiency, and moderate pulmonary hypertension with right ventricular systolic pressures $36 \mathrm{~cm}$ above that of the right atrium. There were no signs of vegetations, and her ejection fraction was preserved. Renal ultrasound with Doppler performed due to proteinuria of $22 \mathrm{mg} / \mathrm{dL}$ (normal 1-14 mg/dL) showed no signs of intrinsic disease.

She was transfused one unit of packed red blood cells for her anemia. Musculoskeletal and chest pain was managed initially with ketorolac and later with naproxen for their concurrent anti-inflammatory effects. Furosemide and enalapril were started for preload and after-load reduction with gradual resolution of fluid overload over 24 to 48 hours. During this period, she had several episodes of small-volume hemoptysis that improved in conjunction with diuresis. Given the clinical and laboratory findings as well as mitral valve involvement without a prior history of cardiac disease, there was a concern for an underlying infectious or inflammatory process.

Rheumatology was consulted on day two of admission. There was a concern for possible vasculitis versus an atypical presentation of rheumatic fever. Workup was extended to include chest CT that showed cardiac findings consistent with the echocardiogram but also showed right-sided lung abnormalities including, centrilobular ground-glass, intralobular septal thickening, and alveolar opacification consistent with hemorrhage, as shown in Figure 1. These findings were less severe in the right upper lobe and worse in the right middle and lower lobes. There was associated right-sided hilar and mediastinal adenopathy. Pulmonology evaluated the patient for possible bronchoscopy, but as hemoptysis was already improving, this was deferred. While lab results were pending, given the significant multiorgan involvement, she was started on high-dose methylprednisolone daily for three days with conversion to oral prednisone taper thereafter. Azithromycin was started as prophylaxis against atypical infections while undergoing the initial high-dose steroid course. A more extensive infectious disease workup was not undertaken due to a lack of evidence for another source after initial labs and imaging. She had good clinical improvement, with a resolution of tachycardia and hypoxemia, as well as a significant improvement in her chest pain.

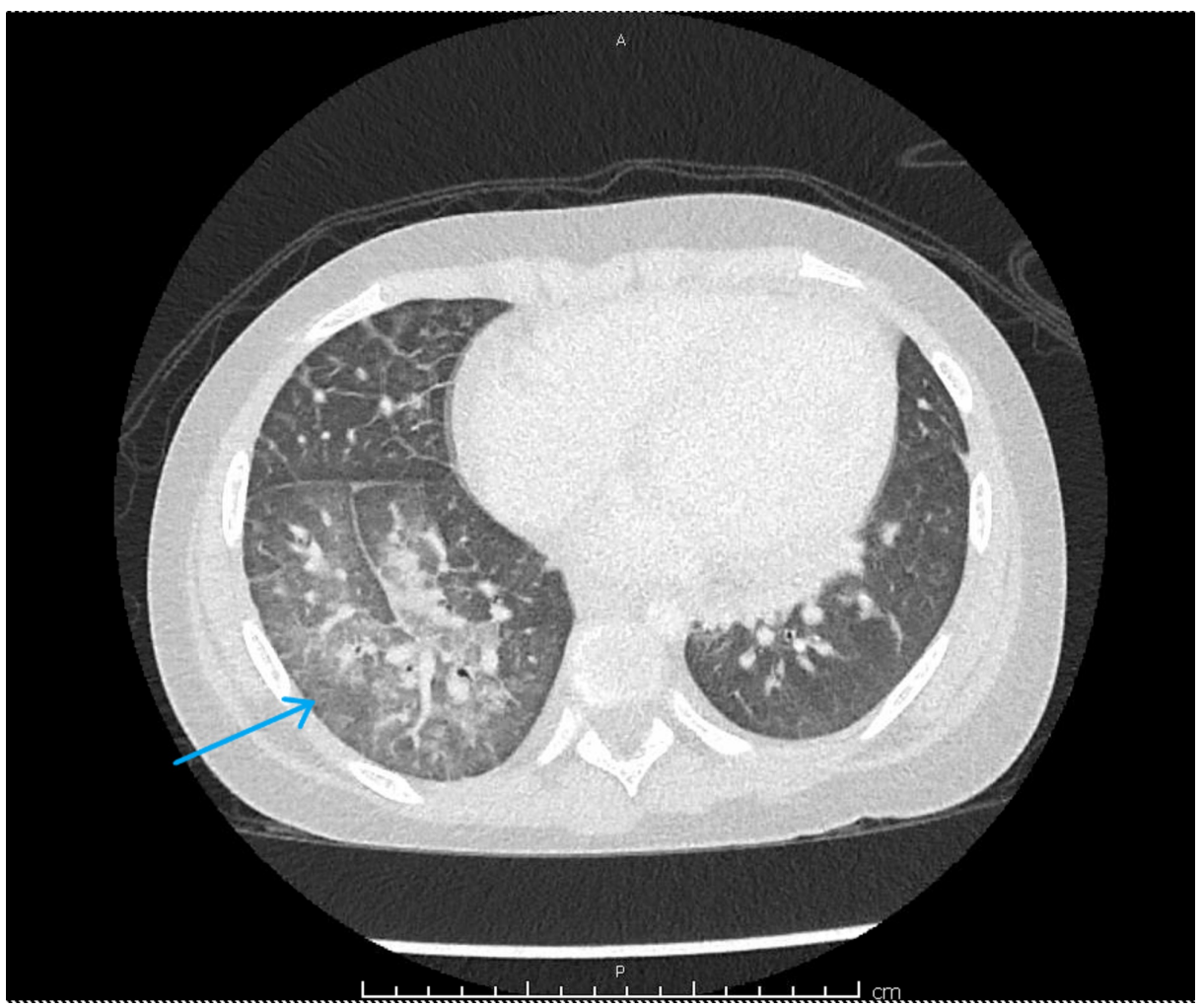

FIGURE 1: CTA chest

Diffuse inflammatory changes with alveolar hemorrhage, as well as ground-glass opacities, noted in the right middle and lower lobes with left lower lobe atelectasis and hilar lymphadenopathy.

CTA - Computed Tomography Angiogram

On days three and four of admission, the first rheumatologic lab results returned significant for significantly 
positive antinuclear antibodies (ANA) and elevated streptolysin $\mathrm{O}$ Ab and anti-DNase B. Other pertinent rheumatologic studies (all negative) are also shown in Table 1. Throat culture was performed, which was negative but was collected after starting azithromycin. Penicillin $\mathrm{G}$ was initiated for the treatment of rheumatic fever with the first dose on day five of admission.

The patient continued to improve and was discharged on day nine on admission with home nursing support and close outpatient multispecialty follow-up. She was discharged on furosemide, enalapril, naproxen, and monthly penicillin injections. Her post-discharge course included multiple emergency department visits for recurrent chest pain but this has gradually improved. Her family was tested and treated prophylactically with amoxicillin as her brother, sister, and mother were found to be group A strep carriers.

She has continued to follow with cardiology and rheumatology. Blood work after discharge showed the normalization of ESR within four weeks and a gradual reduction in her antistreptolysin O (ASO) titer. Repeat chest CT scan three months after presentation demonstrated a resolution of ground-glass and right-sided consolidations with minimal residual left lower lobe atelectasis and resolving lymphadenopathy. An echocardiogram performed five months after her initial presentation showed mild mitral regurgitation, mild aortic valve insufficiency, normalization of left heart chamber size, no pulmonary hypertension, and normal biventricular function. She has not had further episodes of fluid overload and has tolerated gradual reduction in her diuretic. She will continue to receive monthly penicillin G injections until the age of 18 .

\section{Discussion}

We offer this case of rheumatic pneumonia as an example of a rapidly progressive case of ARF with multiorgan involvement. The most recent report of this entity from a search of Ovid MedLine and Pubmed is from 2005 with seven English-language reports in the preceding two decades (Table 2) [7-16]. Our patient's presentation was severe and somewhat atypical, as there was significant anemia with a history of recent weight loss. She also reported non-migratory arthralgias of her shoulder, elbows, wrists, back, hips, and knees for two months prior to presentation. In addition, an elevated IgG at 2450 units/mL with a positive ANA supports an autoimmune process. These could suggest a previous episode or episodes of ARF that went without a diagnosis. In this case, her current presentation would be consistent with a recurrent acute episode exacerbating subacute or chronic changes. Throat culture was negative in our patient though it was obtained after antibiotics were administered. However, she did have elevated ASO and anti-DNase B titers and multiple culture-positive first-degree contacts in the same household. In low-risk populations, either ASO titers or throat culture data should guide diagnosis if there are other equally likely entities. In our patient, an elevated ANA initially, along with a history of oral ulcers, hemoptysis, and proteinuria, complicated diagnosis, but lupus and a vasculitis workup were otherwise negative and rapid improvement of diffuse symptomatic carditis and resolution of pulmonary findings were more consistent with ARF. Autopsy reports in earlier series have shown interstitial infiltrates, alveolar hemorrhage, and other inflammatory changes as were seen on CT chest in this report [16-17]. Close multispecialty observation over 18 months has not yielded a different diagnosis, and follow-up rheumatologic testing was negative. Prompt initiation of symptomatic treatment for cardiac dysfunction, the addition of pulse steroids, as well as the initiation of penicillin when ASO returned positive are believed to have been crucial in the improvement noted in this patient's clinical course. Most large-scale studies are from the 1950-1960s, and do not show benefit from steroid administration but have significant inter-study variability [18-19]. The initiation of these therapies is thus empiric and guided by a patient's clinical course. 


\begin{tabular}{|c|c|c|c|c|c|c|c|c|c|c|c|}
\hline Year & Age & Sex & Location & ARF episode & $\begin{array}{l}\text { Lung } \\
\text { involvement }\end{array}$ & Steroid use & Steroid course & $\begin{array}{l}\text { Throat } \\
\text { culture }\end{array}$ & $\begin{array}{l}\text { ASO } \\
\text { (T.U.) }\end{array}$ & $\begin{array}{l}\text { anti- } \\
\text { Dnase B }\end{array}$ & Result \\
\hline 2005 & 13 & Female & Qatar & First & Right & Yes & Not reported & $\begin{array}{l}\text { Not } \\
\text { reported }\end{array}$ & 250 & $\begin{array}{l}\text { Not } \\
\text { performed }\end{array}$ & Survived \\
\hline 2002 & 3 & Female & $\begin{array}{l}\text { Pernambuco, } \\
\text { Brazil }\end{array}$ & First & Right & Prednisone & $1 \mathrm{mg} / \mathrm{kg}$ daily & $\begin{array}{l}\text { Not } \\
\text { reported }\end{array}$ & 600 & $\begin{array}{l}\text { Not } \\
\text { performed }\end{array}$ & Survived \\
\hline 2001 & 18 & Male & Spain & Second & $\begin{array}{l}\text { Left lower } \\
\text { lobe }\end{array}$ & Prednisone & $\begin{array}{l}60 \mathrm{mg} \text { daily, } 2 \text { month } \\
\text { taper }\end{array}$ & No growth & 400 & $\begin{array}{l}\text { Not } \\
\text { performed }\end{array}$ & Survived \\
\hline 1995 & 19 & Male & Utah, US & First & Right & Prednisone & $\begin{array}{l}1.5 \mathrm{mg} / \mathrm{kg} \text { daily, taper not } \\
\text { reported }\end{array}$ & No growth & 400 & $1: 340$ & Survived \\
\hline 1991 & $\begin{array}{l}\text { Less than } \\
6\end{array}$ & $\begin{array}{l}\text { Not } \\
\text { reported }\end{array}$ & Mexico & $\begin{array}{l}\text { First - } 2 \text { cases; Second - } \\
11 \text { cases }\end{array}$ & $\begin{array}{l}13 \text { cases, } \\
\text { variable }\end{array}$ & Not reported & Not reported & $\begin{array}{l}\text { Not } \\
\text { reported }\end{array}$ & $\begin{array}{l}\text { Not } \\
\text { reported }\end{array}$ & $\begin{array}{l}\text { Not } \\
\text { reported }\end{array}$ & $\begin{array}{l}9 \text { of } 13 \\
\text { fatal }\end{array}$ \\
\hline 1990 & 10 & Female & Ethiopia & Not reported & Right & Not reported & Not reported & $\begin{array}{l}\text { Not } \\
\text { reported }\end{array}$ & $\begin{array}{l}\text { Not } \\
\text { reported }\end{array}$ & $\begin{array}{l}\text { Not } \\
\text { reported }\end{array}$ & Death \\
\hline 1987 & 10 & Male & Hawaii, US & First & $\begin{array}{l}\text { Left lower } \\
\text { lobe }\end{array}$ & No & None & $\begin{array}{l}\text { Not } \\
\text { reported }\end{array}$ & 1600 & $\begin{array}{l}\text { Not } \\
\text { performed }\end{array}$ & Survived \\
\hline 1985 & 14 & Male & Israel & Second & Bilateral & Prednisone & $\begin{array}{l}\text { 60mg daily, tapered over } \\
>1 \text { month }\end{array}$ & Jo growth & 833 & $\begin{array}{l}\text { Not } \\
\text { performed }\end{array}$ & Survived \\
\hline 1982 & $\begin{array}{l}\text { Not } \\
\text { reported }\end{array}$ & $\begin{array}{l}\text { Not } \\
\text { reported }\end{array}$ & Romania & Not reported & $\begin{array}{l}6 \text { cases, } \\
\text { variable }\end{array}$ & Not reported & Not reported & $\begin{array}{l}\text { Not } \\
\text { reported }\end{array}$ & $\begin{array}{l}\text { Not } \\
\text { reported }\end{array}$ & $\begin{array}{l}\text { Not } \\
\text { reported }\end{array}$ & $\begin{array}{l}6 \text { of } 6 \\
\text { Survived }\end{array}$ \\
\hline 1975 & 13 & Male & Arizona, US & First & Bilateral & Hydrocortisone & $80 \mathrm{mg}$ every 6 hours & $\begin{array}{l}\text { Not } \\
\text { reported }\end{array}$ & 333 & $\begin{array}{l}\text { Not } \\
\text { performed }\end{array}$ & Death \\
\hline
\end{tabular}

TABLE 2: Cases of rheumatic pneumonia found in a search of medical literature in the English language after 1975

References [7-16]

ARF - Acute Rheumatic Fever, ASO (T.U.) - Antistreptolysin O, Todd Units

The limitations to this report include the absence of throat culture prior to the initiation of antibiotics as well as the absence of a lung biopsy.

\section{Conclusions}

Rheumatic pneumonia is poorly understood. In recorded cases of rheumatic pneumonia, the pulmonary manifestations vary from pulmonary congestion out of proportion to observed left heart failure, infiltrative and consolidative processes, to alveolar hemorrhage and even the need for mechanical ventilation. Necropsy reports after fulminant cases have reported various degrees of necrosis and Masson bodies indicative of fibrotic changes. Although there can be a significant pulmonary disease, initiation of penicillin with or without high-dose steroids (as we utilized in the case above), addressing cardiac manifestations with diuretics and afterload reduction, and symptomatic care typically lead to significant improvement. Other than the use of penicillin as a secondary prophylaxis against future episodes, there remains significant debate on the benefit of other therapies. In our patient, her repeat CT chest only three months after presentation demonstrated the resolution of ground-glass opacities and resolving mediastinal adenopathy. Though she still has cardiac sequelae resulting from her carditis, her pulmonary findings (including pulmonary function testing) and symptoms have completely resolved. More prospective studies are needed to understand the presentation, severity, and outcome of pulmonary manifestations in patients with acute rheumatic fever.

\section{Additional Information}

\section{Disclosures}

Human subjects: Consent was obtained by all participants in this study. Conflicts of interest: In compliance with the ICMJE uniform disclosure form, all authors declare the following: Payment/services info: All authors have declared that no financial support was received from any organization for the 
submitted work. Financial relationships: All authors have declared that they have no financial relationships at present or within the previous three years with any organizations that might have an interest in the submitted work. Other relationships: All authors have declared that there are no other relationships or activities that could appear to have influenced the submitted work.

\section{References}

1. Benedek TG: The history of bacteriologic concepts of rheumatic fever and rheumatoid arthritis . Semin Arthritis Rheum. 2006, 36:109-123. 10.1016/j.semarthrit.2006.05.001

2. Kothari S: Of history, half-truths, and rheumatic fever . Ann Pediatr Cardiol. 2013, 6:117-120. 10.4103/09742069.115251

3. Carapetis JR, McDonald M, Wilson NJ: Acute rheumatic fever. Lancet. 2005, 366:155-168. 10.1016/S01406736(05)66874-2

4. Erdem G, Mizumoto C, Esaki D, et al.: Group A streptococcal isolates temporally associated with acute rheumatic fever in Hawaii: differences from the continental United States. Clin Infect Dis. 2007, 45:20-24. $10.1086 / 519384$

5. Beaudoin A, Edison L, Introcaso CE, et al.: Acute rheumatic fever and rheumatic heart disease among children-American Samoa, 2011-2012. MMWR Morb Mortal Wkly Rep. 2015, 64:555-558.

6. Gewitz MH, Baltimore RS, Tani LY, et al.: Revision of the Jones criteria for the diagnosis of acute rheumatic fever in the era of Doppler echocardiography. A scientific statement from the American Heart Association. Circulation. 2015, 131:1806-1818. 10.1161/CIR.0000000000000205

7. EI-Menyar A, AI-Hroob A, Numan MT, Gendi SM, Fawzy IM: Unilateral pulmonary edema: unusual presentation of acute rheumatic fever. Pediatr Cardiol. 2005, 26:700-702. 10.1007/s00246-005-0893-8

8. Saraiva LR: Rheumatic pneumonia. Ann Rheum Dis. 2002, 61:477. 10.1136/ard.61.5.477-a

9. de la Fuente J, Nodar A, Sopeña B, et al.: Rheumatic pneumonia. Ann Rheum Dis. 2001, 60:990-991. 10.1136/ard.60.10.990

10. Burgert SJ, Classen DC, Burke JP, Veasy LG: Rheumatic pneumonia: reappearance of a previously recognized complication of acute rheumatic fever. Clin Infect Dis. 1995, 21:1020-1022. 10.1093/clinids/21.4.1020

11. Vázquez-Antona C, Calderón-Colmenero J, Attié F, et al.: Rheumatic cardiopathy in children younger than 6 years of age [Article in Spanish]. Arch Inst Cardiol Mex. 1991, 61:143-147.

12. Ephrem D: Rheumatic pneumonia in a 10-year old Ethiopian child . East Afr Med J. 1990, 67:740-742

13. Yamamoto LG, Seto DS, Reddy DV: Pneumonia associated with acute rheumatic fever . Clin Pediatr (Phila). 1987, 26:198-200. 10.1177/000992288702600412

14. Raz I, Fisher J, Israeli A, Gottehrer N, Chisin R, Kleinman Y: An unusual case of rheumatic pneumonia . Arch Intern Med. 1985, 6:1130-1131. 10.1001/archinte.1985.00360060198032

15. Geormäneanu M, Iagăru N, Petraru D, Popescu-Micloşanu S: Uncommon pneumonia associated with acute poststreptococcal glomerulonephritis. Morphol Embryol (Bucur). 1982, 28:145-152.

16. Serlin SP, Rimsza ME, Gay JH: Rheumatic pneumonia: the need for a new approach . Pediatrics. 1975, 56:1075-1078.

17. Goldring D, Behrer MR, Brown G, Elliott G: Rheumatic pneumonitis. Part II. Report on the clinical and laboratory findings in twenty-three patients. J Pediatr. 1958, 53:547-565. 10.1016/s0022-3476(58)80145-6

18. Cilliers A, Adler AJ, Saloojee H: Anti-inflammatory treatment for carditis in acute rheumatic fever . Cochrane Database Syst Rev. 2015, 28:003176. 10.1002/14651858.CD003176.pub3

19. Karthikeyan G, Guilherme L: Acute rheumatic fever. Lancet. 2018, 392:161-174. 10.1016/S01406736(18)30999-1 